\title{
Dutta's Innovative work to prevent PPH
}

\author{
Dr. Dilip Kumar Dutta*1, Dr. Indranil Dutta ${ }^{2}$, Dr. Mriganka Mouli Saha ${ }^{3}$ \\ ${ }^{1}$ Consulting Gynaecologist, Department of Obstetrics and Gynaecology, Director, GICE Clinic, West Bengal, India. \\ ${ }^{2}$ Assistant Professor, Department of Obstetrics and Gynaecology, IQ City Medical College, West Bengal, India. \\ ${ }^{3}$ Department of Obstetrics and Gynaecology, IPGMER and SSKM Hospital, Kolkata, West Bengal, India
}

*Correspondence to: Dr. Dilip Kumar Dutta, A-9/7, Kalyani Nadia West Bengal-741235, India; E-mail: drdilipdutta@yahoo.com

Received: June 02, 2018; Accepted: June 20, 2018; Published: June 24, 2018;

\section{Introduction}

Haemorrhage killed more women than any other complications of pregnancy in the history of mankind. Placenta previa, abruption placenta and uterine rupture are in three important causes of ante partum haemorrhage seen frequently at tertiary level care hospital claiming high maternal mortality and morbidity till date present existing surgical technique to tackle major degree placenta previa is found to be not effective method to control haemorrhage during LUCS causing high incidence of maternal mortality and morbidity. Hence to prevent uncontrolled haemorrhage due to major degree placenta previa, author has advocated new surgical technique (Dutta's) to prevent uncontrolled haemorrhage during LUCS.

\section{Methodology}

New technique (Dutta's) were undertaken during LUCS operation in a stepwise Manner > delivery of baby following lower segment incision $>$ bilateral uterine artery ligation $>$ inj. Tranexamic acid (1000 gm) intramuscular $>$ oxytocin infusion ( 10 unit) $>$ delivery of placenta and its membrane and checked properly $>$ if tear or laceration interrupted suture by catgut 1-0 > uterine wound were closed in two layers by catgut no 1 after securing bleeding from placental site or uterine wound $>$ abdominal wall closed, after toileting the abdominal cavity, in presence of good uterine contraction. Main objective of the study to find out how to reduce maternal mortality and morbidity, after advocating (Dutta's) new technique, during LUCS operation, for major degree placenta previa.

Benefits: Operative findings: good effectiveness to control bleeding, caesarean hysterectomy not required, immediate post operative bleeding - less. Maternal mortality - nil, maternal morbidity - less, good fetal outcome. Follow up up to two years: mentrual cycle normal, future fertility - good

\section{Conclusion}

Hence by adopting the new surgical technique (Dutta's) during LUCS it was found to be simple, safe, quick procedure, reduce perfusion pressure, permits time for further steps thereby avoiding unnecessary ligation of hypogastric, bill and caesarean hysterectomy. Maternal mortality and morbidity were also found to be reduced. It is a suitable technique for rural based tertiary care hospital in absence of adequate blood transfusion facility.

\section{Reference}

1. Damania KR, Salvi VS, Walvekar Vs. A Study of maternal mortality over 20 years. J Obst Gyn India 1989; 39: 61-5.

2. Motwani MN, Sheeth J. Maternal Mortality from APH: Review of 20 years death. J Obst Gyn India 1990; 39: 364-6.

3. Bowie JD, Rochester D, Cadkin AV, et al. Accuracy of placental localization by ultrasound. Radiology 1978; 128: 177-80.

4. Cotton D, Read J, Paul R, et al. The conservative aggressive management of placenta praevia. Am J Obstet Gynecol 1989; 137: 687-95.

5. Davis ME, Campbell A. The management of placenta praevia in the Chicago Lyingin Hospital. Surg Gynaec and Obst 1946; 83: 777.

6. Evans, McShane. The efficacy of hypogastric artery ligation in obstetric haemorrhage. Surg Gynaecol Obstet 1985; 160: 250-3.

7. Hill DJ, Beischer NA. Placenta praevia without antepartum haemorrhage Aust N Z J Obstet Gynaeclo 1980; 20: 21-3.

8. Macafee CHG. Modern views on the management of placenta praevia. Post Card, Ded Journ 1949; 25: 297

9. McClure N, Dornal JC. Early identification of placenta praqevia (see comments). Br J Obstet Gynaecol 1990; 98-625.

10. Render S. Placenta preavia and previous lower segment caesarean secton. Surg Gynaec and Obst 1954; 98: 625.

11. Weiser EB. Managing second trimester placenta praevia. Contrib Gynecol Obstet 1980; 15: 187.
Citation:

Dilip Kumar Dutta, Indranil Dutta, Dr. Mriganka Mouli Saha (2018) Dutta's Innovative work to prevent PPH. Integr Gyn Obstet $J$ Volume 1(1): 1-1. DOI: 10.31038/IGOJ.2018104 